\title{
Antibiogram of the Micrococcus luteus, Pseudomonas aeruginosa, Staphylococcus epidermidis and Staphylococcus intermedius isolated from the bovine frozen semen
}

\author{
Shahid Hussain Abro $^{1 *}$, Rani Abro ${ }^{2}$, Rahamatullah Rind ${ }^{1}$, Asghar Ali \\ Kamboh $^{1}$, Akeel Ahmed Memon ${ }^{3}$, Aijaz Ali Channa ${ }^{4}$, Hakimzadi \\ Wagan $^{5}$, Hassina Baloch ${ }^{1}$ and Bakhtawar Wagan ${ }^{6}$ \\ 1. Department of Veterinary Microbiology, Faculty of Animal Husbandry and Veterinary Sciences, Sindh \\ Agriculture University Tandojam, Pakistan \\ 2. Department of Animal Nutrition, Faculty of Animal Husbandry and Veterinary Sciences, Sindh Agriculture \\ University Tandojam, Pakistan \\ 3. Department of Animal Reproduction, Faculty of Animal Husbandry and Veterinary Sciences, Sindh Agriculture \\ University Tandojam, Pakistan \\ 4. Department of Theriogenology, Faculty of Veterinary Science, University of Veterinary and Animal Sciences, \\ Lahore, Pakistan \\ 5. Department of Agricultural Economics, Faculty of Social Sciences, Sindh Agriculture University Tandojam, \\ Pakistan \\ 6. Department of Farm Structure, Faculty of Agricultural Engineering, Sindh Agriculture University Tandojam, \\ Pakistan \\ *Corresponding author's email: shahidabro9@yahoo.com

\section{Citation} \\ Shahid Hussain Abro, Rani Abro, Rahamatullah Rind, Asghar Ali Kamboh, Akeel Ahmed Memon, Aijaz Ali \\ Channa, Hakimzadi Wagan, Hassina Baloch and Bakhtawar Wagan. Antibiogram of the Micrococcus luteus, \\ Pseudomonas aeruginosa, Staphylococcus epidermidis and Staphylococcus intermedius isolated from the bovine \\ frozen semen. Pure and Applied Biology. Vol. 5, Issue 2, 2016, pp204-212. \\ http://dx.doi.org/10.19045/bspab.2016.50027
}

\begin{tabular}{llll}
\hline \hline Received: 21/12/2015 & Revised: 04/02/2016 & Accepted: 10/02/2016 & Online First: 16/02/2016 \\
\hline \hline
\end{tabular}

\section{Abstract}

The presence of harmful microbes may negatively influence semen quality. Antibiotic used in the semen extender should be evaluated in order to prevent contamination and infertility. In this study, Antibiogram evaluation of Micrococcus luteus, Pseudomonas aeruginosa, Staphylococcus epidermidis and Staphylococcus intermedius were detected from frozen semen of cattle. Different antibiotics such as amikacin, ampicillin, amoxicillin, cephalexin, erythromycin, gentamicin, neomycin, ofloxacin and sulphamethoxazole/trimethoprim were tested against the isolated bacterial species. Ofloxacin, amikacin, cephalexin and amoxicillin were highly effective against Micrococcus luteus. The organism was found equally effective to erythromycin, gentamycin and neomycin. Amikacin, ofloxacin, erythromycin, neomycin and ampcillin were the most effective against the Pseudomonas aeruginosa. However, amoxicillin, cephalexin and 
sulphamethoxazole/trimethoprim were not shown any response. Staphylococcus epidermidis was found highly sensitive to amikacin. While antibiotics amoxicillin, erythromycin, and cephalexin completely failed to give response against the organism. Staphylococcus intermedius was noted highly sensitive to neomycin, amikacin and ampicillin. Overall, amikacin and neomycin were found the most effective antibiotics against these bacterial isolates determined from bovine semen samples.

Key words: Antibiogram; Bacterial species; Bovine; Semen

\section{Introduction}

Artificial insemination (AI) has been useful method that is practiced for breeding of cattle and other domestic animal species all over the world. This method is the best tool which is benefiting farmers to obtain high quality genetic potential from proven animals [1-2]. Routinely, semen packaged in straws approximately $0.25 \mathrm{ml}$ or $0.5 \mathrm{ml}$ in volume for thawing and storage. The thaw straws and polythene bags containing semen are transported using liquid nitrogen $[3,4]$. However, there is a risk of contamination of semen from microbes during the packaging, storage and transportation can influence quality of semen and reproductive efficiency [5].

Generally, fresh semen contains some of non-pathogenic microbes that are neither harmful nor affecting the semen quality. However, the presence of large number or harmful microbes may negatively influence semen quality [6]. Frozen semen could get contaminated with pathogenic and nonpathogenic microbial agents during processing and handling. The microbes in the semen can transfer serious diseases in recipient animals and/or could be potential source of infections in different parts of genital tract $[7,8]$.

The semen production centers have to ensure that the processed semen should be free from environmental microbes and donor bulls. The presence of Acinectobacter cacloaceticus, Brucella suis, Chlamydophila abortus, Coxiella burnetti, Enterobactercoccus, Enterobacter cloacae, Escherichia coli, Histophilus somni, Staphylococcus aureus, Pseudomonas aeroginosa, Pantoeau agglomerans, Staphylococcus sciuri, Ureaplasma diversum, Stenotrophomonas maltophilia, Micrococcus, Leptospira, Corynebacteriu and Flavobacterium species been reported in the frozen semen of farm animals [9-17]. Furthermore, the presence of bacterial species in bull semen may varies according to different breeds [18].

In normal practice, antibiotics are added to semen extender in order to control various microorganisms and to improve the quality of bovine semen [19]. Generally, combination of streptomycin and penicillin are added to diluents in extender for bovine semen $[20,21]$. The combination of lincospectin, gentamycin and tylosin diluted in bovine semen extender that is sufficiently effective for controlling in microorganism such as; Campylobacter fetus Mycoplasma and Pseudomonas species [22]. In contrast, the combination of lincomycin, gentamicin, spectinomycin and tylosin (LGST) were added in bull semen extender to check the efficiency of this combination of the antibiotics against mycoplasma species. The combination failed to control growth of mycoplasma species in the semen extender contained LGST antibiotic mixture. This indicated the various antibiotics used in semen extender are not necessary to control infection or microbial contamination [23]. Traditionally, addition of pencillin in semen extender is not responding against different microbes e.g. brucella, cornybacteria, mycobacteria, vibrio, hemophillus, ureaplasmas and mycoplasmas species [24]. Antibiotic resistance is an emerging problem for different microorganism contaminants in frozen semen of cattle, used for artificial 
insemination. Therefore, present study is designed to determine the efficacy of different antibiotics against the bacterial isolates identified from bovine semen used for artificial insemination.

\section{Materials and methods}

Bovine semen samples (one hundred) were obtained under sterile hygienic condition from the local semen production centers at Karachi and Rohri. The semen samples were contained in straws and sterilized bijou bottles in artificial insemination kits, which contained liquid nitrogen and brought to the Central Veterinary Diagnostic Laboratory, TandoJam, Pakistan.

Different dehydrated media were used for the culture or presence of any bacteria in the frozen semen samples. Dehydrated nutrient agar (Difco, 2000), MacConkey agar (Difco, 2000) and blood agar (Difco, 2000) were rehydrated according to recommendation of manufacturer. The medium was thoroughly mixed and autoclaved at $121^{\circ} \mathrm{C}, 15 \mathrm{lb}$ pressure for $15 \mathrm{~min}$. The blood agar medium was kept at room temperature and added with 5\% sheep blood (defibrinated). These media were incubated aerobically at $37^{\circ} \mathrm{C}$ for $24 \mathrm{~h}$ and checked for microbial growth. The bovine semen samples were inoculated by streaking method on blood, nutrient and MacConkey's agar media. The bacterial colonies were observed for bacterial growth. The bacteria that were grown on the media, sub-cultured to obtain pure culture of isolated organism. The single colony was obtained from the sub-culture and analyzed for staining. The bacteria grown on different media were observed for morphological and colony characteristic.

The bacterial colonies were taken for the pure culture and for the biochemical characteristics and sugar fermentation abilities. Various biochemical tests e.g. oxidase, coagulase catalase, urease, aesculin test, gelatin liquefaction, bile tolerance, indole production, methyl blue, Hugh and
Leifson's test, methyl red, nitrate reduction Vogus-Proskauer test, triple sugar iron agar, Simmon's citrate and sugar fermentation tests were performed as prescribed by [2527]. These biochemical and sugar fermentation tests were performed for the identification and confirmation of the isolates contained in the frozen semen samples.

The antibiotic sensitivity was performed as described by Bauer et al. [28]. The different antibiotics; amikacin, ofloxacin, neomycin, chloromphenicol, cephalexin, amoxicillin, kanamycin, ampicillin, gentamicin, sulphamethoxazole/ trimethoprim, tetracycline and erythromycin were used during the study. The Muller Hinton agar (Difco) was used and incubated at $37^{\circ} \mathrm{C}$ for 15 minutes. Bulks of pure culture colonies were suspended evenly in 2-4 sterile normal saline solution in order to match barium chloride standard for antibiotic sensitivity. A sterile cotton swab was dipped into the suspended and culture was smeared on the surface of Muller Hinton agar in such a way that all agar surface was covered evenly with the bacterial suspension, then incubated at $37^{\circ} \mathrm{C}$ for 15 minutes for plate to dry. The desired antibiotic disc were kept on agar surface with disc dispenser and lightly pressed with sterile forceps to make it adhere to surface. The plate was closed, wrapped in polythene bag, inverted (medium and disc upward) and incubated overnight at $37^{\circ} \mathrm{C}$. The zone of inhibition was observed as a clear area, free from growth around the disc and a clear zone of inhibition made against organism. The zone of inhibition by the antibiotics was recorded in millimeter from the center of disc to the ending edges of zone. The antibiotic sensitivity was classified into highly, quite, moderately, weakly sensitive and resistant depending on the antibiotics, its contents in the disc and size of zone. 
No clear zone around antibiotic discs

Clear zone with $1-2 \mathrm{~mm}$ diameter around antibiotic discs +

Clear zone with $2-5 \mathrm{~mm}$ diameter around antibiotic discs ++

Clear zone with $5-10 \mathrm{~mm}$ diameter around antibiotic discs +++

Clear zone with $10-15 \mathrm{~mm}$ diameter around antibiotic discs ++++

\section{Results and discussion}

In this study, bovine semen samples were examined for the contamination or presence of bacterial species. Frozen bovine semen samples were found positive for Micrococcus luteus, Pseudomonas aeruginosa, Staphylococcus epidermidis and Staphylococcus intermedius. These bacterial organisms detected from the bovine semen samples were examined for the efficacy of different antibiotics.

The sensitivity of Micrococcus luteus was recorded high against the ofloxacin, amikacin, cephalexin and amoxicillin and their sensitivity against the species were observed $95.75 \%, 63.15,60.50$ and $60.50 \%$ respectively (Table 1). Previously, it has been reported that cephalexin, chloromphenicol, tetracycline, ampcillin were highly effective against the Micrococcus luteus [29, 30]. MICs of ofloxacin were elevated concentration 0.08 $\mathrm{ug} / \mathrm{ml}$ effective to Micrococcus species [31]. The organism was found equally effective to erythromycin, gentamycin and neomycin the action against the organism recorded as $39.35 \%$. The organism was weakly sensitive to sulphamethoxazole (4\%). The minimum inhibition concentration (MIC) of nisin against the organism showed the concentration of $0.156 \mathrm{ug} / \mathrm{ml}$ [32].

Multidrug resistance is an emerging problem of Pseudomonas aeruginosa and getting more attention due to nosocomial pathogen from the environment [33]. Antibiogram profile of Pseudomonas aeruginosa was investigated; amikacin, ofloxacin, erythromycin, neomycin and ampcillin were the most effective against the organism and their activity was noted 94\%, 87.15\%, $60.50 \%, 60.50 \%$ and $64.50 \%$ (Table 1) respectively. It has been reported that the organism showing high resistance to ceftazidime and ceftriaxone and comparatively less resistance to amikacin, ciprofloxacin, levofloxacin and oflaxacin. However, Pseudomonas aeruginosa showed lower resistance to combinations of cefoperazone, peperacillin, sulbactum and tazobactum [34]. Amikacin showed 73.52\% activity against Pseudomonas aeruginosa [35]. In this study, amoxicillin, cephalexin and sluphamethoxazole were not affective against the Pseudomonas aeruginosa. Similarly, our findings are consentient to previous report [36] amoxicillin, moxifloxacin, ceftraxone, spiramycin, levfoloxacin and cefotaxime were inactive against the micro-organisms. However, the micro-organism showed low sensitivity against the organism [35]. Decreasing the antibiotic susceptibility to Staphylococcus species is major concern in controlling its infections [37]. In this study, Staphylococcus epidermidis was found highly sensitive to amikacin $93.00 \%$ (Table 1). Staphylococcus epidermidis showed high sensitivity to amikacin, cephalotin, chloromphenicol, cephazolin, deoxycycline, norafloxacin and Vancomycin [38]. The organism was found quite sensitive to ampicillin, gentamycin, neomycin and ofloxacin its susceptibility against the antibiotics was recorded as $39.35 \%, 27.35 \%$, $22.50 \%$ and $22.50 \%$ respectively (Table 1 ). 
Table 1. Antibiotic sensitivity against the bacterial species isolated from bovine frozen semen

\begin{tabular}{|c|c|c|c|c|c|}
\hline Bacterial species & Antibiotic disc & $\begin{array}{l}\text { Inhibitory } \\
\text { zone (mm) }\end{array}$ & $\begin{array}{l}\text { Sensitivity } \\
(\%)\end{array}$ & $\begin{array}{l}\text { Sensitivity } \\
\text { Induction }\end{array}$ & Degree of sensitivity \\
\hline \multirow{8}{*}{$\begin{array}{l}\text { Micrococcus } \\
\text { luteus }\end{array}$} & Amoxycillin & 12.55 & 60.50 & ++++ & Highly sensitive \\
\hline & Erythromycin & 10.00 & 39.35 & +++ & Quite sensitive \\
\hline & Gentamicin & 10.00 & 39.35 & +++ & Quite sensitive \\
\hline & Cephalexin & 12.55 & 60.50 & ++++ & Highly sensitive \\
\hline & Amikacin & 13.55 & 63.15 & ++++ & Highly sensitive \\
\hline & Ofloxacin & 15.55 & 94.75 & ++++ & Highly sensitive \\
\hline & Neomycin & 10.00 & 39.35 & +++ & Quite sensitive \\
\hline & $\begin{array}{l}\text { Sulphamethoxazole/ } \\
\text { Trimethoprim }\end{array}$ & 01.00 & 04.00 & + & Weakly sensitive \\
\hline \multirow{8}{*}{$\begin{array}{l}\text { Pseudomonas } \\
\text { aeruginosa }\end{array}$} & Neomycin & 12.55 & 60.50 & +++ & Highly sensitive \\
\hline & Erythromycin & 12.55 & 60.50 & ++++ & Highly sensitive \\
\hline & Amikacin & 15.00 & 94.00 & ++++ & Highly sensitive \\
\hline & Ofloxacin & 14.50 & 87.15 & ++++ & Highly sensitive \\
\hline & Ampicillin & 11.50 & 64.50 & ++++ & Highly sensitive \\
\hline & Amoxycillin & 0 & 0 & - & Not sensitive \\
\hline & Cephalexin & 0 & 0 & - & Not sensitive \\
\hline & $\begin{array}{l}\text { Sulphamethoxazole/ } \\
\text { Trimethoprim }\end{array}$ & 0 & 0 & - & Not sensitive \\
\hline \multirow{8}{*}{$\begin{array}{l}\text { Staphylococcus } \\
\text { epidermidis }\end{array}$} & Neomycin & 07.55 & 22.50 & +++ & Quite sensitive \\
\hline & Gentamicin & 08.55 & 27.32 & +++ & Quite sensitive \\
\hline & Cephalexin & 0 & 0 & - & Not sensitive \\
\hline & Ampicillin & 10.00 & 39.35 & +++ & Quite sensitive \\
\hline & Erythromycin & 0 & 0 & - & Not sensitive \\
\hline & Amikacin & 15.00 & 93.00 & ++++ & Highly sensitive \\
\hline & Amoxycillin & 0 & 0 & - & Not sensitive \\
\hline & Ofloxacin & 07.55 & 22.50 & +++ & Quite sensitive \\
\hline \multirow{8}{*}{$\begin{array}{l}\text { Staphylococcus } \\
\text { intermedius }\end{array}$} & Neomycin & 14.00 & 83.48 & ++++ & Highly sensitive \\
\hline & Gentamicin & 08.50 & 28.13 & +++ & Quite sensitive \\
\hline & Cephalexin & 0 & 0 & - & Not sensitive \\
\hline & Ampicillin & 11.55 & 64.50 & ++++ & Highly sensitive \\
\hline & Erythromycin & 0 & 0 & - & Not sensitive \\
\hline & Amikacin & 12.55 & 60.50 & ++++ & Highly sensitive \\
\hline & Amoxycillin & 0 & 0 & - & Not sensitive \\
\hline & Ofloxacin & 06.55 & 19.46 & +++ & Quite sensitive \\
\hline
\end{tabular}

Previously reported data regarding Staphylococcus epidermidis support our findings [39]. In this study, antibiotics amoxicillin, erythromycin and cephalexin completely failed to give response against the Staphylococcus epidermidis. . It has been studied antibiotic pattern of Staphylococcus epidermidis and observed that high 
antibiotic resistance against cefixime, pencillin, ceftazidime, oxacillin, cephepime and nalidixic acid [38]. The findings in this study are partially in agreement with previous study [40]. In-vitro susceptibility of Staphylococcus epidermidis and observed that their sensitivity was variable against the antibiotics benzyl penicillin, tetracycline, neomycin, chloromphenicol, erythromycin and gentamycin [40].

There is an increasing trend in antimicrobial resistance among clinical isolates of Staphylococcus intermedius of small animals [41]. The cells of Staphylococcus intermedius were noted highly sensitive to neomycin (83.48\%), amikacin $(60.50 \%)$ and ampicillin $(64.50 \%)$ and quite sensitive against gentamycin $(28.13 \%)$ and ofloxacin (19.46\%). However, Staphylococcus intermedius showed resistance against cephalexin, amoxicillin and erythromycin. It was investigated that antibiotic resistance of Staphylococcus intermedius found below $10 \%$ against the amoxi-clavulanic acid and fluoroquinoles and cefalexin. also, the organism exhibited increasing resistance trend toward amoxicillin, ampcillin, enrofloxcin and cefovecin [41].

\section{Conclusion}

In summary, Micrococcus luteus was highly susceptible to ofloxacin, amikacin, cephalexin and amoxicillin and weakly responding to sulphamethoxazole. Pseudomonas aeruginosa was shown high activity to amikacin, ofloxacin, erythromycin, neomycin, ampcillin and conferring the resistance to amoxicillin, cephalexin and sluphamethoxazole. Staphylococcus epidermidis was found highly susceptible to amikacin and amoxicillin, while erythromycin and cephalexin were not effective against the organism. Staphylococcus intermedius was noted highly susceptible to neomycin, amikacin and ampicillin and weakly susceptible against gentamycin and ofloxacin. The organism showed resistance against cephalexin, amoxicillin and erythromycin. Overall, amikacin and neomycin were found the effective antibiotics against these bacterial isolates determined from bovine semen samples.

\section{Authors' contributions}

Conceived and designed the study, SH Abro, R Abro, R Rind, AA Kamboh, AA Memon \& AA Channa, conducted experiments: $\mathrm{SH}$ Abro, R Abro \& H Baloch, Analysed data: SH Abro, H Wagan \& B Wagan, Written manuscript: SH Abro, $\mathrm{H}$ Wagan \& B Wagan.

\section{Acknowledgement}

The Central Veterinary Diagnostic Laboratory (CVDL) Tandojam, Sindh, Pakistan, is highly acknowledged for providing platform and necessary facilities for the research. The authors are grateful to Dr. Parkash Dewani, CVDL, Tandojam, Sindh, Pakistan for his help in the research work.

\section{References}

1. Funk DA (2006). Major advances in globalization and consolidation of the artificial insemination industry. J Dairy Sci 89(4): 1362-1368.

2. Verkerk G (2003). Pasture-based dairying: challenges and rewards for New Zealand producers. Theriogenology 59(2): 553-561.

3. Bwanga CO, Einarsson S \& RodriguezMartinez H (1991). Cryopreservation of boar semen. II: Effect of cooling rate and duration of freezing point plateau on boar semen frozen in mini- and maxi-straws and plastic bags. Acta Vet Scand 32(4): 455-461.

4. Weitze KF, Stampa E, Richter L, Willmen T \& Waberski D (1991). Fertility of frozen boar semen: influence of packaging, number of inseminations and seminal plasma. Reprod Domest Anim Suppl 1: 139-142. 
5. Russell PH, Lyaruu VH, Millar JD, Curry MR \& Watson PF (1997). The potential transmission of infectious agents by semen packaging during storage for artificial insemination. Anim Reprod Sci 47(4): 337-342.

6. Thacker BJ, Larsen RE, Joo HS \& Leman AD (1984). Swine diseases transmissible with artificial insemination. $J$ Am Vet Med Assoc 185(5): 511-516.

7. Diemer T, Weidner W, Michelmann HW, Schiefer HG, Rovan E \& Mayer F (1996). Influence of Escherichia coli on motility parameters of human spermatozoa in vitro. Int $J$ Androl 19(5): 271-277.

8. Thibier M \& Guerin B (2000). Hygienic aspects of storage and use of semen for artificial insemination. Animal Reproduction Science 62(2000): 233251.

9. Bielanski A, Bergeron $\mathrm{H}$, Lau PC \& Devenish J (2003). Microbial contamination of embryos and semen during long term banking in liquid nitrogen. Cryobiology 46(2): 146-152.

10. Corona A \& Cherchi R (2009). Microbial quality of equine frozen semen. Anim Reprod Sci 115(1-4): 103109.

11. D'Angelo M, Pavão DL, Melo GM, Rojas N, Souza RJ \& Athayde C (2006). Acceptable microorganisms concentration in a semen sample for in vitro embryo production. Braz J Microbiol 37: 571-572.

12. Hobson N, Chousalkar KK \& Chenoweth PJ (2013). Ureaplasma diversum in bull semen in Australia: its detection and potential effects. Aust Vet J 91(11): 469-473.

13. Kruszewska D \& TylewskaWierzbanowska S (1997). Isolation of Coxiella burnetii from bull semen. Res Vet Sci 62(3): 299-300.
14. Ramaswamy V, Andrew MJ, Saravanabava K \& Venugopal AT (1990). Microbial flora of bovine semen and its antibiogram. Journal of Veterinary and Animal Sciences 21: 152-154.

15. Ramaswamy V, Kirubaharan JJ, Jesudas MJA, Roy P \& Venugopalan AT (1994). Prevalence of Microbes in Frozen Cattle Semen and Their Antibiotic Spectra. Indian Journal of Animal Reproduction 15: 50-52.

16. Ramaswamy V, Latha N, Gnanasubramanian $\mathrm{T}$ \& Manickam $\mathrm{R}$ (2002). Aerobic bacteria in buffalo semen and their antibiogram. Indian Journal of Animal Reprodution 23:117119.

17. Schlafer DH \& Miller RB (2007). Female Genital System. In: Grant MaxieM (ed.), Pathology of Domestic Animals Volume 3, 5th edn. Saunders Elsevier Philadelphia 429-564.

18. Sannat C, Nair A, Sahu SB, Sahasrabudhe SA, Kumar A, Gupta AK \& Shende RK (2015). Effect of species, breed, and age on bacterial load in bovine and bubaline semen. Veterinary World 8(5): 461-468.

19. de Jarnette JM, Marshall CE, Lenz RW, Monke DR, Ayars WH \& Sattler CG (2004). Sustaining the fertility of artificially inseminated dairy cattle: The role of the artificial insemination industry. Journal of Dairy Science 10(3): 87-93.

20. Andrabi SMH, Ahmad N, Abbas A \& Anzar M (2001). Effect of two different antibiotic combinations on fertility of frozen buffalo and Sahiwal bull semen. Pakistan Veterinary Journal 21: 166169.

21. Sansone G, Nastri M.JF \& Fabbrocini A (2000). Storage of buffalo (Bubalus bubalis) semen. Animal Reproduction Science 62: 55-76. 
22. Guerin B \& Thibier M (1993). Value of adding antibiotics to frozen bovine semen: the example of mycoplasmas and campylobacters. Contraception Fertilite Sexualite 21: 753-759.

23. Visser IJR, Laaka TEA \& Jansen HB (1999). Failure of antibiotics gentamycin, tylosin, lincomycin and spectinomycin to eliminate Mycoplasma bovis in artificially infected frozen bovine semen. Theriogenology 51(4): 689-697.

24. Shin SJ, Lein DH, Patten VH \& Ruhnke (1988). A new antibiotic combination for frozen bovine semen; Control of Mycoplasmas, Ureaplasmas, Compylobacter fetus subsp venerealis and Heamophilus somnus. Theriogenology 29: 577-592.

25. Abro SH, Wagan R, Tunio MT, Kamboh AA \& Munir M (2009). Biochemical activities of bacterial species isolated from the frozen semen of cattle. Jornal of Agriculture and Social Sciences, 5(4): 109-113.

26. Christensen H, Bisgaard M, Angen $\mathrm{O}$ \& Olsen JE (2002). Final classification of Bisgaard taxon 9 as Actinobacillus arthritidis sp. nov. and recognition of a novel genomospecies for equine strains of Actinobacillus lignieresii. Int J Syst Evol Microbiol 52(4): 1239-1246.

27. Khalil MA \& Gabbar A (1992). Procedures in veterinary microbiology. Field document No. 6. 2nd Ed. CVDL, Tandojam, Sindh, Pakistan.

28. Bauer AW, Kirby WMM, Sheriss JC, Turck M . (1966). Antibiotic susceptibility testing by standardised single method. Am J clin Path 2(45): 493-496.

29. Fazlani SA, Khan SA, Faraz S \& Awan MS (2011). Antimicrobial susceptibility of bacterial species identified from mastitic milk samples of camel. African
Journal of Biotechnology 10(15): 29592964.

30. Rind R \& Khan, TS (2000). Antibiogram sensitivity of bacterial organisms identified from surgical and nonsurgical wounds of Animals. Pak J Biol Sci 10(3): 1719-1723.

31. von Eiff C \& Peters G (1998). In vitro activity of ciprofloxacin,ofloxacin, and levofloxacin against micrococcus species and Stomatococcus mucilaginosus isolated from healthy subjects and neutropenic patients. Eur $J$ Clin Microbiol Infect Dis 17(1): 890893.

32. Chandrasekar V, Knabel SJ \& ARC (2015). Modeling development of inhibition zones in an agar diffusion bioassay. Food Science 3(5): 394-403.

33. Walkty A, DeCorby M, Nichol K, Karlowsky JA, Hoban DJ \& Zhanel GG (2008). In vitro activity of ceftobiprole against clinical isolates of Pseudomonas Aeruginosa obtained from Canadian intensive care unit (ICU) patients as part of the CAN-ICU Study. J Antimicrob. Chemother 62(1): 206-208.

34. Abbas SH, Khan MZI, Naeem M, Adil M, Naz SM, Khan A \& Khan MU (2015). Sensitivity patterns of Pseudomonas aeruginosa isolates obtained from clinical specimens in Peshawar. J Ayub Med Coll Abbottabad 27(2): 329-332.

35.Sultana S, Mawla N, Kawser S, Akhtar N \& Ali KM (2015). Current microbial isolates from wound swab and their susceptibility pattern in a private medical college hospital in Dhaka city. Delta Med Col J 3(1).

36. Planquette B, Péron J, Dubuisson E, Roujansky A, Laurent V, Le Monnier A, Legriel S, Ferre A, Bruneel F, Chiles PG \& Bedos JP (2015). Antibiotics against Pseudomonas aeruginosa for COPD exacerbation in ICU: a 10-year 
retrospective study. Int $J$ Chron Obstruct Pulmon. Dis 2(10): 379-388

37. Safari M, Saidijam M, Bahador A, Jafari R \& Alikhani MY (2003). High prevalence of multidrug resistance and metallo-beta-lactacillin-resistant and methicillin-susceptible Staphylococcus aureus bacteremia: a meta-analysis. Clin Infect Dis 1(7): 53-59.

38. Mohaghegh MA, Ghazvini K, Jafari R, Alikhani MY, Marzieh Safari M, Garamjan GAA, Falahi J \& Bordbar D (2015). Retrospective study on the prevalence and antibiotic resistance pattern of Staphylococcus aureus and Staphylococcus epidermidis among patients suspicious of bacteremia During 2006 - 2011. Int J Enteric Pathog 2(3): 1-5.
39. Bhatt P, Tandel K, Singh A, Mugunthan M, Grover N \& Sahni AK (2015). Species distribution and antimicrobial resistance pattern of Coagulase-negative Staphylococci at a tertiary care centre. Med J Arm Forc India 1(12): 1-4.

40. Archer GL, Vishavski N \& Stiver HG (1995). Pencillin and tetracycline resistant plasmids in Staphylococcus epidermidis. Antimicrob-agents chemoter. 20: 359-365.

41. Beever L, Bond R, Graham PA, Jackson B, Lloyd DH \& Loeffler A (2015). Increasing antimicrobial resistance in clinical isolates of Staphylococcus intermedius group bacteria and emergence of MRSP in the UK. 